\title{
Psicoterapia e psicofarmacologia: a percepção de psicólogos
}

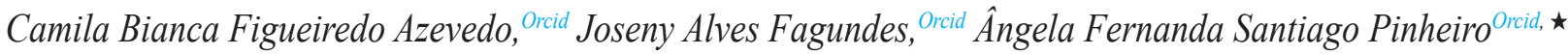 \\ Faculdade de Saúde Ibituruna, Montes Claros, MG, Brasil
}

\section{Resumo}

Este trabalho tem como objetivo, compreender como os psicólogos inseridos na Secretaria Municipal de Saúde de Montes Claros - MG, no ano de 2015, veem estes três eixos pertinentes: psicoterapia, psicofármacos e a relação existente entre eles. Trata-se de um estudo do tipo quantitativo e qualitativo, de corte transversal, de uma amostra censitária, com enfoque exploratório e delineamento de estudo de caso. Foi realizada uma análise de 27 questionários de psicólogos no período de janeiro a julho de 2015. Através da discussão e dos resultados, foi possível compreender que a maioria dos psicólogos percebem os psicofármacos como auxiliadores no processo psicoterápico e que concordam que alguns pacientes necessitam utilizar os psicofármacos durante este processo. Conclui-se então que, esta pesquisa possibilitou compreender como se encontra, atualmente, o cenário do atendimento psicológico na rede da Secretaria Municipal de Saúde de Montes Claros - MG.

Palavras-chave: psicofármacos; psicoterapia; atitudes e prática em saúde; visão de psicólogos.

\section{Psychotherapy and psychopharmacology: the perception of psychologists}

\begin{abstract}
This paper aims to promote an understanding on how psychologists of the Department of Public Health Care of the city of Montes Claros - MG, in 2015, see these three relevant areas: psychotherapy, psychotropic drugs, and the relationship between them. It refers to a study, of quantitative kind, cross-sectional, exploratory approach and design case study. It was conducted by an analysis of 27 questionnaires Psychologists in the period between January and July 2015. Through discussion and results, it was possible to understand that most psychologists perceive psychiatric drugs as helpers in the psychotherapeutic process and agree that some patients need to use psychoactive drugs during this process. In conclusion then, this research enabled us to understand as is currently the scene of psychological care in the municipal health network of Montes Claros- MG.
\end{abstract}

Keywords: psychotropic drugs; psychotherapy; attitudes; practice; overview of psychologists.

\section{Introdução}

Consideráveis mudanças vêm ocorrendo nas últimas décadas, referentes à atitude de psicoterapeutas e psiquiatras, no que diz respeito ao uso dos psicofármacos aliados a psicoterapia. Devido ao comprometimento com a efetividade terapêutica, tornou-se necessário que os profissionais de saúde mental, das diversas modalidades terapêuticas busquem novos conhecimentos, já que, a abordagem dos problemas emocionais, através de uma visão exclusivamente biológica ou psicológica, pode impedir o paciente de obter o tratamento mais adequado. Quando há então, uma possibilidade de comunicação entre os profissionais existe também, uma possibilidade de troca de conhecimentos que pode ser benéfica para os profissionais e para o paciente (SAFFER, 2007).

Antes de compreender o que vem acontecendo no cenário atual, no que se refere à percepção do psicólogo em relação à psicoterapia e aos psicofármacos, é necessário tecer considerações sobre a Reforma Sanitária, visto que, ela adentrou no âmbito do social como um projeto de grande importância para a cidade de Montes Claros - MG e para a sociedade (MENDONÇA, 2009).

Nessa linha de expressão, a Reforma Sanitária foi uma Reforma Democrática, não anunciada ou alardeada na área da saúde; que nasceu da luta contra a ditadura. Dessa forma, a reforma baseou-se no tema Saúde e De-

\footnotetext{
^Endereço para correspondência: Faculdade de Saúde Ibituruna. Av. Nice 99, Ibituruna. Montes Claros/MG - CEP: 39.401-303.E-mail: millahazevedo@hotmail.com, josenyyalves@yahoo.com.br, angelapsicologia@gmail.com
}

mocracia; em seguida estruturou-se nas universidades, no movimento sindical, bem como em experiências regionais de organização de serviços (AROUCA, 1998).

Esse movimento social consolidou-se na $8^{\text {a }}$ Conferência Nacional de Saúde, em 1986. De forma inédita, mais de cinco mil representantes de todos os seguimentos da sociedade civil brasileira discutiram um novo modelo de saúde para o Brasil. Como resultado, foi garantido ao povo, na Constituição Brasileira, através de emenda popular, o direito à saúde; consistindo, assim, um dever do Estado. Nessa perspectiva, a Reforma Sanitária tratou-se, então, de um movimento popular que visava várias mudanças na área da saúde. Dentre as mudanças, a reforma buscava, principalmente, a universalidade, a integralidade e a igualdade de direitos na saúde e a responsabilização do estado, que na percepção dos precursores, deveria suprir as necessidades em saúde da população brasileira (AROUCA, 1998).

A cidade de Montes Claros - MG adentra então, neste cenário de significativas e importantes mudanças brasileiras, em 1983, quando foram feitas denúncias sobre a situação dos doentes mentais na cidade; cobrando assim, uma providência dos poderes locais (MENDONÇA, 2009).

A chegada do trem de ferro marcou esse período, na cidade de Montes Claros. A linha ligava Rio de Janeiro, Belo Horizonte e o Norte de Minas à Bahia. Considerado essa chegada um marco do progresso e do desenvolvimento de uma região, o trem de ferro também foi usado para transportar àqueles que impediam o seu crescimento. O trem transportava os "doentes mentais" de todo o estado de Minas Gerais para hospícios, como o de Barbacena, excluindo-os do convívio social (MACHADO, 2009). 
Em 1985, foi realizada em Montes Claros, uma reunião que continha a participação de líderes do governo brasileiro que tinha o intuito de se debater as propostas do governo, as quais deveriam encerrar o ciclo autoritário de presidentes da República com a candidatura de Tancredo Neves. O secretário municipal de Saúde de Montes Claros, na época, José de Saraiva Felipe, enviou uma carta da cidade de Montes Claros que reafirmava os princípios e postulados do simpósio realizado em 1979, na Câmera dos Deputados. Foi então, a partir da cidade de Montes Claros, que sucederam várias outras reuniões para aprofundar e minuciar a "futura realização da proposta denominada de Nova República; sobretudo, no que se refere ao processo de unificação entre o INAMPS, Ministério da Saúde e a passagem da Central de Medicamentos da Previdência Social para a saúde" (CORDEIRO, 2004).

Após o trágico falecimento do Presidente Trancredo Neves, José Sarney tomou posse em 1985 e nomeou o ministro Waldir Pires que teve grande sensibilidade para as propostas de reforma da saúde e da seguridade social. José Saraiva Felipe, o secretário de Montes Claros, foi nomeado para a Secretaria de Assistência Médica do Ministério da Previdência e Assistência Social - MPAS, colocando assim, Montes Claros como um marco importante para a história da reforma Sanitária (CORDEIRO, 2004).

Atualmente, Montes Claros possui dois serviços substitutivos para a assistência em saúde mental, propostos pela Reforma, um CAPS II (Centro de Atenção Psicossocial) e um CAPSad (Centro de Atenção Psicossocial Álcool e Drogas). Além disso, Montes Claros, que se localiza na região sudeste do Brasil, é considerada uma cidade polo em atendimento à saúde e, inclusive, em saúde mental da região norte do Estado de Minas Gerais, visto que, atende populações oriundas de várias cidades situadas em seu entorno (CORDEIRO, 2004).

Diante destes pressupostos e para dar prosseguimento a esta pesquisa, é necessário adentrar no âmbito do tratamento psicoterápico e psicofarmacológico. É importante lembrar que o tratamento psicoterápico difere do psicofarmacológico. Diante dessa visão, torna-se imprescindível diferenciar psicoterapia e psicofarmacologia (KIMURA, 2005). Entretanto, como a psicofarmacologia faz parte de um estudo sobre medicamentos, surge à necessidade de explicar, previamente, sobre a medicalização.

A medicalização é um recurso terapêutico em que um problema e/ou comportamento não médico é definido com um transtorno, doença ou problema médico, sendo delegada ao profissional médico, a responsabilidade pela prescrição do medicamento. (CONRAD, 1975 apud CARVALHO et al., 2015). Já os psicofármacos, são medicamentos que auxiliam no alivio do sofrimento mental, podendo ser indispensáveis para o tratamento de algumas psicopatologias (DALMOLIN et al., 2009 apud FRANCO, 2012). São substâncias que interferem em funções do sistema nervoso central proporcionando a redução do desconforto causado pela sintomatologia dos transtornos mentais (DALMOLIN et al., 2009 apud FRANCO, 2012).
A decisão do uso da medicação exige um cuidado meticuloso, pois a decisão pode ser influenciada pelos próprios conflitos e desejos inconscientes do psiquiatra (FREY; MABILDE; EIZIRIK, 2004). Trata-se de um assunto polêmico e multifacetado, uma vez que, provavelmente, existem psicólogos concordantes com o uso e com a eficácia dos psicoterápicos paralelamente à psicoterapia e outros discordantes (GENTIL et al., 2007). Este conflito é possível ser observado nos casos em que os psiquiatras favorecem apenas o uso dos psicofármacos e os psicólogos preconizam apenas a psicoterapia (DALMOLIN et al., 2009 apud FRANCO, 2012).

A ação de medicalizar é intitulada como "medicalização do social", isto é; ela funciona como um controle social que atinge toda a vida do sujeito, em todas as dimensões; pois, legitima e empossa-o do papel de doente. Nesse viés, é preciso questionar a respeito da eficácia psicoterápica, dos seus efeitos colaterais e, principalmente, acerca da serventia para pacientes portadores de sofrimentos psicológicos; pois, aparentemente, a tristeza, o medo da morte, o desamparo, a solidão, a inquietude, o receio, a insegurança, o vazio existencial ou, até mesmo, a falta de felicidade são ocorrências constantes na vida do ser humano (BIRMAN, 2000).

A patologia pode ser considerada objetiva pelo médico na sua prática. No entanto, essa percepção do patologista não faz com que seu paciente seja desprovido de subjetividade. Adentrando, assim, na necessidade de que este, provavelmente, terá de ser visto além do fator biológico. Diante dessa colocação, abre-se espaço à psicoterapia (CANGUILHEM, 2006).

A psicoterapia é uma técnica que usa dos mais variados instrumentos do método em que é embasada. Sendo, portanto, uma técnica válida e positiva, visto que utiliza de instrumentos, com eficácia comprovada cientificamente (RIBEIRO, 1984).

A psicoterapia é também, uma forma de autoconhecimento, de crescimento e aprendizagem. Dessa forma, a psicoterapia não é apenas uma teoria ou técnica que trata de pessoas doentes, mas uma ação entre duas pessoas, que resulta em maior envolvimento de ambos com a realidade. Consequentemente, psicoterapeuta e paciente, juntos, podem estabelecer uma relação benéfica, que fará com que o paciente, ao adentrar sua própria realidade, encontre meios para amenizar seu sofrimento psicológico (RIBEIRO, 1984).

A psicoterapia já é um efetivo recurso de mudança e, com a força do contato humano e dos psicofármacos, quando necessários, garante a eficácia do tratamento. "Isto nos permite sonhar com um futuro no qual a escolha do medicamento ou a indicação de psicoterapia sejam feitas, especificamente, analisando as condições de cada paciente, caso-a-caso" (BEZERRA, 2008, p. 2).

Atualmente, percebe-se que a psicoterapia e a psicofarmacologia são eficazes no tratamento de pessoas com Transtornos Mentais, entretanto, ambas possuem benefícios e limitações. Na psicofarmacologia, o alivio dos sintomas é mais rápido, mas existem efeitos colaterais adversos. 
Na psicoterapia, normalmente, o acompanhamento é feito semanalmente e o progresso e observado no decorrer do tempo. No entanto, os casos de transtornos mentais graves demandam uma ação mais imediata. Sendo assim, recentes estudos indicam que os dois métodos terapêuticos, quando combinados, são mais eficazes para a saúde mental do paciente do que isoladamente (FRANCO, 2012).

A necessidade de investigar o tema surgiu a partir de vivências, em sala de aula, na Faculdade de Saúde Ibituruna de Montes Claros - MG, durante as aulas de Psicofarmacologia - uma das disciplinas lecionadas no curso de Psicologia - no momento em que foi explicada a importância de se prescrever medicamentos em alguns casos de sofrimento e agravos psicológicos. Nesse ínterim, surgiram questionamentos e inquietações a respeito da percepção do psicólogo em relação ao uso de psicofármacos aliados à psicoterapia. Diante destes questionamentos, surgiu a necessidade de se realizar esta pesquisa na cidade de Montes Claros - MG.

Embora existam poucos estudos acerca do tema, é possível encontrar correlação desta pesquisa com a pesquisa de Kamura, realizada em 2005, na cidade de São Paulo, que buscou compreender a visão dos psicólogos sobre a medicação no tratamento psicoterápico de orientação psicodinâmica, no qual concluiu que os Psicólogos reconhecem a importância dos psicofármacos como auxiliadores para o tratamento analítico.

Com a evolução da ciência, atualmente, existem diversas construções sobre a importância da relação psiquiatra/ psicólogo, quando ela é pautada no comprometimento ético e científico, para o alívio do sofrimento humano. Assim, a partir das pontuações supracitadas, percebendo, através delas, a importância do local que será o campo de pesquisa para o cenário brasileiro e a relevância do tema, este trabalho objetiva promover uma melhor compreensão de como os psicólogos da Secretaria Municipal de Saúde de Montes Claros - MG, no ano de 2015, veem estes três eixos pertinentes: psicoterapia, psicofármacos e a relação existente entre eles. Bem como, a relação do psicólogo com o psiquiatra, a fim de se possibilitar uma contribuição científica à prática clínica, na cidade de Montes Claros.

É fundamental compreender, nesse caminho, a importância desses eixos temáticos, uma vez que, a relação da psicofarmacologia com a psicoterapia tem se tornado algo constante e essencial (SAFFER, 2007).

\section{Materiais e métodos}

Trata-se de um estudo do tipo quantitativo, de corte transversal, com enfoque exploratório e delineamento de estudo de caso. Conforme a informação colhida junto à Secretaria Municipal de Saúde de Montes Claros, estavam inseridos, no município, 37 psicólogos, os quais seria o público-alvo dessa pesquisa. Vale destacar, assim, que eles atuam nos Centro de Atenção Psicossocial (CAPS), ESF Estratégia de Saúde da Família (ESF), Centro de Atenção Psicossocial Álcool e Drogas (CAPSad), Consultório de Rua, Serviços como o Melhor em

Fractal, Rev. Psicol., v. 30 - n. 2, p. 281-290, 2018
Casa, O centro de Reabilitação para Idosos, O Centro de Referência em Doenças Infecciosas e a gestão de Saúde Mental de Montes Claros - MG.

Cumpre ressaltar que a cidade de Montes Claros foi escolhida como cenário para esta pesquisa, pela disponibilidade e acessibilidade das pesquisadoras ao objeto de estudo, ou seja; trata-se de uma amostragem por conveniência e, por Montes Claros tratar, também de uma cidade que teve importância fundamental na Reforma Sanitária Brasileira.

Esta pesquisa apresenta uma amostra censitária, pois a pesquisa foi realizada com todos os psicólogos, inseridos na Secretária Municipal de Saúde, que se disponibilizaram a responder ao questionário. Os critérios de inclusão desta pesquisa são os psicólogos cadastrados na Secretária Municipal de Saúde de Montes Claros, que aceitaram participar da pesquisa, que compreendem a Língua Portuguesa e que sejam capazes de realizar a leitura, individualmente e sem ajuda de materiais de apoio. Já os critérios de exclusão são os questionários incompletos e ilegíveis.

Em pesquisas com seres humanos submetidos a estudos, critérios como respeito à sua dignidade e à proteção de seus direitos e bem-estar, devem ser preservados, isto se torna primordial também nesta pesquisa. Contudo, apesar desse projeto apresentar os devidos cuidados éticos, ainda assim, apresentam riscos, pois, os psicólogos pesquisados podem ter se sentido constrangidos com alguma das perguntas que constam no questionário. Há também, o risco de quebra de sigilo das respostas dos questionários.

Foi utilizado um questionário com sete questões, sendo estas, abertas e fechadas, adaptado de Kimura (2005). O questionário foi aplicado nas próprias instituições em que o psicólogo está inserido. Foi utilizado, também, o Termo de Consentimento Livre e Esclarecido, fornecido pela Faculdade de Saúde Ibituruna - FASI em 2014. As perguntas tiveram como objetivo principal avaliar a percepção de psicólogos em relação ao uso do medicamento aliado à psicoterapia.

Inicialmente, o projeto foi elaborado e apresentado a Banca de Qualificação do Curso de Graduação em psicologia da Faculdade de Saúde Ibituruna-FASI. Aprovado pela Banca, o Projeto foi, então, encaminhado ao Comitê de Ética. Após a aprovação do comitê de Ética, o primeiro contato com os psicólogos foi iniciado, através do qual foi apresentado e explicado o objetivo do projeto e do Termo de Consentimento Livre Esclarecido, ressaltando sobre a importância e comprometimento com o sigilo. $\mathrm{O}$ termo foi assinado a partir da concordância dos psicólogos sobre a pesquisa. Por conseguinte, foi agendado o dia e o local para a aplicação do questionário, de acordo com a disponibilidade do psicólogo. Cada questionário foi aplicado, individualmente, e, após a aplicação, os dados coletados foram analisados e apresentados como resultado nesta pesquisa. Por conseguinte, foi dada uma devolutiva aos psicólogos através da Secretária Municipal de Saúde de Montes Claros -MG.

Esta pesquisa foi fundamentada nos princípios do Código de Ética do Conselho Regional de Psicologia de 2005 e do Conselho Nacional de Saúde de 14 de janeiro 
de 1987. O primeiro desses princípios foi pautado no IV princípio do código de ética do psicólogo, que diz que "o psicólogo atuará com responsabilidade, por meio do contínuo aprimoramento profissional, contribuindo para o desenvolvimento da Psicologia como campo científico de conhecimento e de prática" (CONSELHO FEDERAL DE PSICOLOGIA [CFP], 2005). Deve-se também, pelo princípio do Conselho Nacional de Saúde que toda pesquisa científica deve assegurar os direitos e deveres que dizem respeito à comunidade científica, aos sujeitos da pesquisa e ao Estado (BRASIL, 1987).

Todo instrumento usado nesta pesquisa obedeceu às normas do Código; pois, conforme o Art. 14, "A utilização de quaisquer meios de registro e observação da prática psicológica obedecerá às normas deste Código e a legislação profissional vigente, devendo o usuário ou beneficiário, desde o início, ser informado" (CFP, 2005).

\section{Resultados e discussão}

A pesquisa teve início no dia 17 de março de 2015 e foi encerrada no dia 31 de março de 2015. Os questionários foram aplicados individualmente nas próprias instituições na qual os psicólogos estão inseridos. Houve uma grande dificuldade das pesquisadoras para localizar e entrevistar os psicólogos, visto que, a maioria deles não possuía horários preestabelecidos. Foram necessárias diversas ligações para localizar os psicólogos e vários comparecimentos das pesquisadoras em um mesmo Serviço de Saúde da prefeitura.

Houve uma alteração na quantidade de psicólogos inseridos na Secretaria Municipal de Saúde, que também dificultou a localização e a aplicação dos questionários desta pesquisa, pois, a informação colhida pelas pesquisadoras no ano de 2014, na Secretaria de Saúde, é de que havia trinta e sete psicólogos atuantes na prefeitura. Contudo, a prefeitura renova os contratos anualmente e, existe então, um novo cadastro de 2015 com vinte e sete psicólogos contratados.

Além da troca dos psicólogos inseridos nos serviços do município, alguns Serviços que em 2014, tinham psicólogos contratados pela prefeitura, têm, atualmente, apenas psicólogos "Residentes", ou seja, psicólogos que fazem parte da Residência Multiprofissional de Saúde da Família e de Saúde Mental. Estes residentes não se enquadram nos objetivos desta pesquisa, visto que, apesar de frequentarem os Serviços de Saúde, não estão cadastrados na Secretaria de Saúde da cidade de Montes Claros - MG.

Em virtude dessas situações, somente vinte e quatro psicólogos responderam os questionários. Dos três psicólogos supracitados que não responderam ao questionário, um psicólogo não foi localizado e os outros dois não se disponibilizaram a responder a pesquisa.

Os serviços no qual os psicólogos estão inseridos e que responderam ao questionário foram o Consultório na Rua, Melhor em Casa, CAPS II, CAPS AD, Centro de Reabilitação para Idosos, Centro de Referência em Doenças Infecciosas, Centros de Saúde dos Bairros São Judas,
Antônio Pimenta, Independência, Santos Reis, Planalto, Major Prates, Maracanã, Vera Cruz e Esplanada e a Coordenadora de Saúde Mental de Montes Claros - MG.

Dos vinte e quatro psicólogos que responderem os questionários, quinze são atuantes pela abordagem da Psicanálise, dois pela Teoria Cognitivo-Comportamental - TCC, um pela Teoria Multifocal de Augusto Cury, dois pela Gestalt, um pela Sistêmica, um pela Abordagem Analítica e um pela Análise do Comportamento. Foi observado então, que mesmo com avanço de outras teorias que embasam a psicologia, ainda há um número maior de psicanalistas atuantes nos Serviços de Saúde da Prefeitura de Montes Claros - MG.

A psicologia possui quatro forças: o comportamentalismo, a Psicanálise, as Teorias humanistas e/ou de autorealização, de Rogers, Maslow, Rollo May, Perls, Reich e outros; e a Teoria Transpessoal de Jung (TELES, 2003). Contudo, nesta pesquisa como se pode observar, foi encontrado um psicólogo que atende seus pacientes pela "Teoria Multifocal de Augusto Cury". Ao pesquisar esta "Teoria" foi encontrado que se trata de uma "Teoria" nova, na autoria de Jorge Augusto Cury. Este autor denomina sua teoria como "uma teoria revolucionária sobre o funcionamento da mente, capaz de criar grande impacto na ciência, estimulando a formação do homem como pensador e engenheiro de ideias" (CURY, 1998). Contudo, baseando em Teles (2003), percebe-se que, essa Teoria não faz parte do rol de Teorias da Psicologia.

Dentre os vinte e quatro psicólogos pesquisados, dez estão inseridos nos Centros de Saúde de Montes Claros, nove nos CAPS II e AD e cinco em Outros Serviços como o Melhor em Casa, O centro de Reabilitação para Idosos, O Centro de Referência em Doenças Infecciosas, a coordenadora de Saúde Mental de Montes Claros - MG e o Consultório na Rua. Desta forma, optou-se por fazer uma divisão destes Serviços em três grupos, sendo eles, o Grupo Centros de Saúde, nomeado nesta pesquisa como grupo Centro de Saúde; o Grupo CAPS, como grupo CAPS; e o grupo dos Outros Serviços (serviço Melhor em Casa, Reabilitação de Idosos, Centro de Referência em Doenças Infecciosas, consultório de Rua e coordenadora de Saúde Mental), como Grupo Três.

As figuras abaixo representam a análise de dados dessa pesquisa.

Figura 1 - você percebe os psicofármacos como auxiliadores no processo psicoterápico?

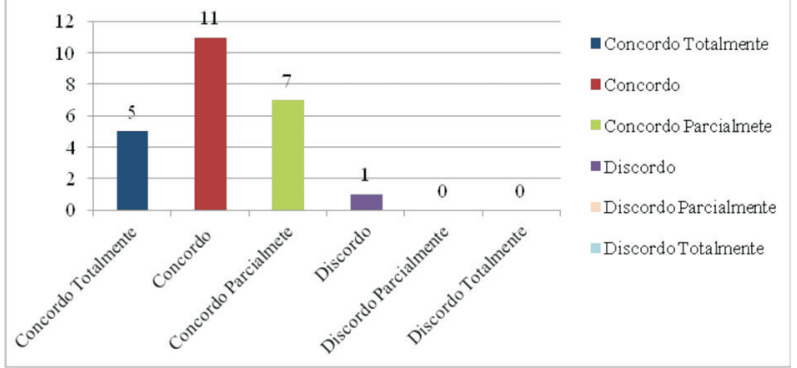

Fonte: Gráfico elaborado pelas autoras com dados de 2015, coletados através de questionários aplicados em psicólogos da Secretária Municipal de Saúde de Montes Claros - MG. 
Através da figura 1, é possível observar que a maioria dos psicólogos percebe os psicofármacos como auxiliadores do tratamento psicoterápico. Podendo observar assim, que existe certa compreensão dos psicólogos sobre o a importância dos benefícios de um tratamento combinado entre psicofarmacologia e psicoterapia para o paciente em sofrimento psicológico.

Diante das respostas dos vinte e quatro psicólogos pesquisados, percebe-se que não há um grande impasse quanto à percepção dos psicofármacos como auxiliadores no processo psicoterápico. Contudo, as respostas são variantes entre, "Concorda totalmente", "Concordam", "Concordam parcialmente" e "Discorda". Percebe-se então que, estes entendem a necessidade da avaliação, caso a caso, do psicólogo para com os seus pacientes, visto que, são diferentes uns dos outros e possuem necessidades diferenciadas.

Figura 2 - Você acredita que os psicofármacos colaboram no processo de adesão do paciente à psicoterapia?

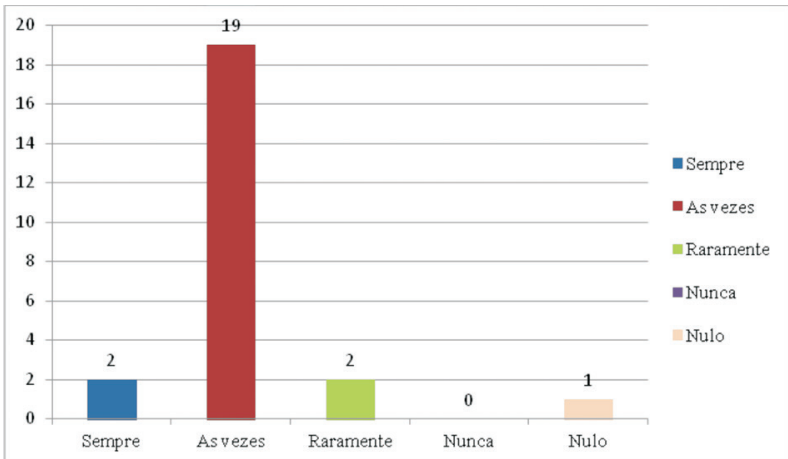

Fonte: Gráfico elaborado pelas autoras com dados de 2015, coletados através de questionários aplicados em psicólogos da Secretária Municipal de Saúde de Montes Claros - MG.

Os psicofármacos, na busca do alívio do sofrimento, auxiliam na capacidade da elaboração da angústia (BENIA, 2005). Além disso, os pacientes com níveis moderados de sofrimento psíquico mantêm a adesão da psicoterapia e os com níveis muito elevados de sofrimento, afetam a motivação e o envolvimento na psicoterapia (BARREIROS, 2012).

Conforme a figura 2, dezenove psicólogos acreditam que os psicofármacos colaboram "Às vezes" na adesão do paciente à psicoterapia. Dentre estes dezenove, dez estão inseridos no Grupo dos Centros de Saúde. Portanto, não houve, nesse grupo, nenhum psicólogo que acredita que os psicofármacos "Sempre", "Raramente" ou "Nunca" colaboram no processo de adesão do paciente à psicoterapia.

No grupo CAPS, um psicólogo acredita que "Sempre", cinco que "Às vezes" e dois acreditam que "Raramente" os psicofármacos colaboram no processo de adesão do paciente à psicoterapia. Nenhum destes acredita que o psicofármaco "Nunca" colabora no processo de adesão. Houve nessa questão também, uma resposta "Nula".

No Grupo Três, quatro acreditam que os psicofármacos colaboram "Às vezes" e um que "Sempre" colabora para o processo de adesão do paciente à psicoterapia. Não houve nenhuma resposta que "Raramente" ou "Nunca" neste grupo.

Fractal, Rev. Psicol., v. 30 - n. 2, p. 281-290, 2018
Desta forma, a maioria dos psicólogos "Concorda" que os psicofármacos favorecem "Às vezes" o processo de adesão do paciente à psicoterapia, pois, provavelmente, compreendem que o processo psicoterápico vai além das inferências psicofarmacológicas. O ser humano, que neste caso, se apresenta como paciente, é um ser subjetivo, sendo que, um método que é eficaz para um paciente pode não ser para outro. Por isso, da necessidade de se examinar os aspectos subjetivos do paciente, usando não só dos seus conteúdos manifestos, mas das associações transferenciais e contratransferências também (POWELL, 2001).

Esta percepção condiz com a ideia de que é necessário compreender a adesão do paciente ao tratamento como um processo. Este processo possui três componentes principais: a noção que o paciente tem de doença, a sua ideia de melhora ou de cura dessa doença e o lugar em que o médico ocupa como imaginário para este paciente (BOTEGA, 2001). Ou seja, a adesão do paciente trata-se de um processo complexo, condizente com as respostas dos pesquisados.

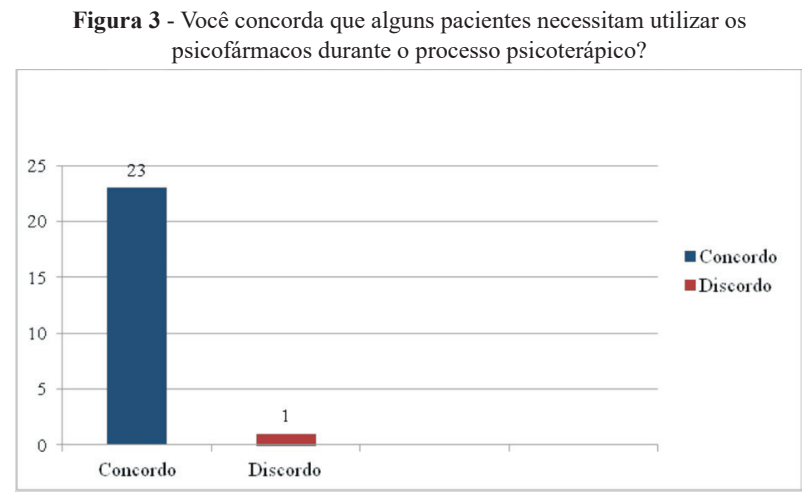

Fonte: Gráfico elaborado pelas autoras com dados de 2015, coletados através de questionários aplicados em psicólogos da Secretária Municipal de Saúde de Montes Claros - MG

Pode-se observar que a maioria dos psicólogos percebe que, os psicofármacos aliviam diferentes tipos de sofrimentos psicológicos (GENTIL et al., 2007).

$\mathrm{O}$ resultado do gráfico mostrou que, os psicólogos acreditam na eficácia do psicofármacos, em alguns casos, sendo coerente com a teoria de que, atualmente, são existem evidencias cientificas da eficácia dos psicofármacos no tratamento de transtornos mentais (BEZERRA, 2008). Além disso, a permanência dos sintomas dificulta a interação do paciente com a equipe de saúde, atrapalhando também, as abordagens terapêuticas psicossociais, podendo prejudicar assim, a sua reintegração social (CARDOSO; GALERA,2009).

É muito importante, que seja considerado, pelo psicoterapeuta e pelo psiquiatra, o desejo do paciente em tomar, ou não, a medicação quando esta se torna necessária para ele. Por isso, a necessidade de examinar os aspectos subjetivos desse paciente sobre o seu tratamento medicamentoso (SAFFER, 2007).

Fazendo uma análise das respostas dos grupos Centros de Saúde, CAPS e o Grupo Três desta pesquisa, no Grupo Centros de Saúde e no Grupo Três, todos os psicólogos "Concordam" que alguns pacientes necessitam utilizar os psicofármacos durante o proces- 
so psicoterápico. Já no Grupo CAPS, oito psicólogos "Concordam" e somente um "Discorda" dessa necessidade. Contudo, mesmo no questionário deste psicólogo, que foi o único a discordar dessa necessidade, foi observado que a sua resposta não condiz com as suas respostas das outras questões, pois, ele "Concorda Parcialmente" que os psicofármacos auxiliam no processo psicoterápico e que encaminha, às vezes, os seus pacientes aos psiquiatras. Por fim, percebe-se então que, 95,83\% dos psicólogos pesquisados, "Concordam" que alguns pacientes necessitam utilizar os psicofármacos durante o processo psicoterápico. Não havendo assim, uma diferença considerável entre os Grupos.

Figura 4 - Em quais situações você percebe a necessidade do uso dos Psicofármacos?

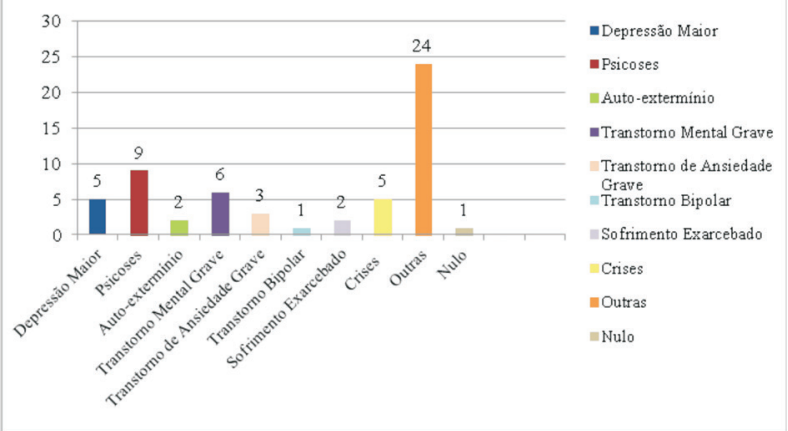

Fonte: Elaborado pelas autoras com dados de 2015, coletados através de questionários aplicados em psicólogos da Secretária Municipal de Saúde de Montes Claros - MG.

A figura 4 representa a terceira questão aberta do questionário e trata de situações que os psicólogos percebem como necessárias o uso do psicofármaco. Como a questão tratava-se de uma questão aberta, cada psicólogo citou mais de uma situação em que consideravam os psicofármacos necessários.

Analisando de uma forma geral, dos 24 pesquisados, nove citaram a Psicose como a situação em que mais necessita do uso dos psicofármacos. Notam-se então, através do gráfico, em especial pelo item "Outras", que os psicólogos ao serem perguntados sobre situações em que percebem a necessidade do uso dos psicofármacos, citaram várias doenças e transtornos. No entanto, a psicose foi a situação mais citada.

Desta forma, percebe-se a necessidade de discorrer sobre o que é psicose. A Psicose é uma desordem mental, em que o pensamento, a resposta afetiva e a capacidade em perceber a realidade podem ser comprometidos. Aliado a estes sintomas, o relacionamento interpessoal pode ser bastante afetado e prejudicado, isto pode interferir de forma substancial no convívio social. Dentre outras características da psicose, estão o prejuízo em perceber a realidade de forma adequada, presença de delírios e alucinações (SADOCK, 2000).

Duas vertentes asseguram o tratamento da psicose, são elas, a vertente farmacológica e a socioeducativa. A base do tratamento psicofarmacológico das Psicoses se resume aos psicofármacos neurolépticos ou antipsicóticos. Vários trabalhos científicos têm demonstrado, na atualidade, a eficácia dessas drogas (TENGAN; MAIA, 2004).

As intervenções psicofarmacológicas objetivam limitar ou atuar de forma a prevenir o comprometimento mental, social ou psicológico do paciente. Essas intervenções devem ser feitas usando uma combinação de psicofármacos e intervenção psicoterápica vigorosa (CABRAL, 2005). Desta forma, é importante a ação medicamentosa aliada à psicoterapia para reduzir o impacto do adoecimento, limitando e prevenindo-o, evitando assim um comprometimento na vida do sujeito (TENGAN; MAIA, 2004).

\footnotetext{
Figura 5 - Para você, o uso do psicofármaco é um meio capaz de auxiliar no alcance de objetivos no tratamento psicoterápico?
}

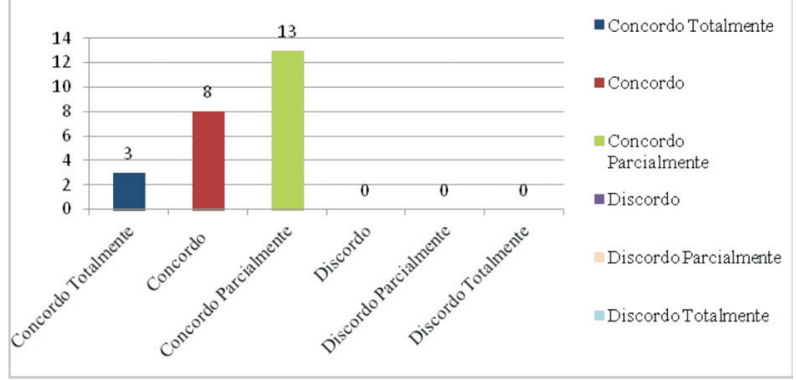

Fonte: Gráfico elaborado pelas autoras com dados de 2015, coletados através de questionários aplicados em psicólogos da Secretária Municipal de Saúde de Montes Claros - MG.

Percebe-se, pela figura 5, que os pesquisados avaliam os psicofármacos como auxiliadores no processo psicoterápico, no que diz respeito ao alcance de objetivos.

O medicamento pode ser um facilitador dos objetivos psicoterápicos, pois a medicação não afeta de forma negativa a psicoterapia, já que, o paciente não se mostra menos motivado com o uso da medicação e a psicoterapia também não interfere negativamente no uso deste (EELLIS, 1999).

Ao comparar os grupos, sendo eles o Grupo Centro de Saúde, o Grupo CAPS e Grupo Três, nota-se que, no Grupo Centro de Saúde, um psicólogo "Concorda Totalmente", dois "Concordam", e sete "Concordam Parcialmente" e nenhum psicólogo "Discorda" que o psicofármaco é capaz de auxiliar no alcance dos objetivos psicoterápicos. No Grupo CAPS, nenhum psicólogo "Concorda Totalmente", quatro "Concordam", cinco "Concordam Parcialmente" e nenhum psicólogo "Discorda" que o psicofármaco é capaz de auxiliar no alcance dos objetivos psicoterápicos. Já no Grupo Três, dois psicólogos "Concordam Totalmente", um "Concorda", e dois "Concordam Parcialmente" e nenhum psicólogo "Discorda" que o psicofármaco é capaz de auxiliar no alcance dos objetivos psicoterápicos.

É possível perceber nos dados coletados que nenhum psicólogo discordou que o psicofármaco é capaz de auxiliar no alcance dos objetivos psicoterápicos, ou seja, neste quesito, a percepção destes é unânime. 
O fato de nenhum Concordar Totalmente sugere, provavelmente, uma visão seletiva, de acordo com a análise dos pacientes, de caso a caso, que aparentemente os psicólogos pesquisados vêm optando por fazer, conforme citado anteriormente neste trabalho, mais propriamente, no gráfico 4.

Figura 6 - Você encaminha os seus pacientes ao psiquiatra?

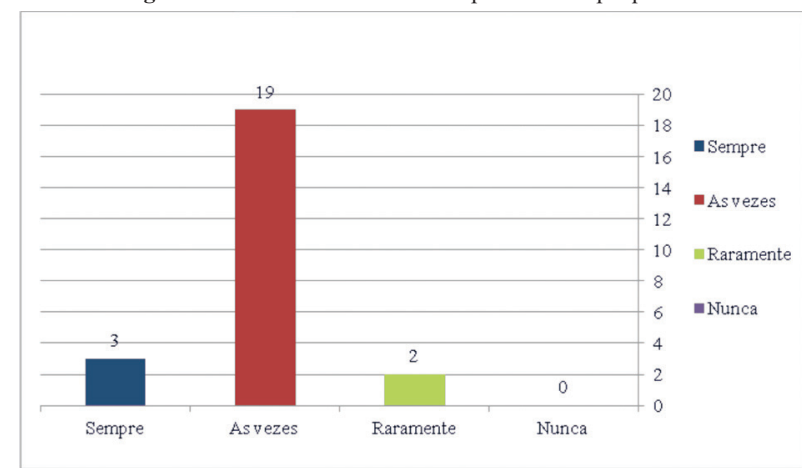

Fonte: Gráfico elaborado pelas autoras com dados de 2015, coletados através de questionários aplicados em psicólogos da Secretária Municipal de Saúde de Montes Claros - MG.

Foi possível observar que, os psicólogos encaminham, mesmo que "Às vezes", seus pacientes aos psiquiatras, compreendendo que os encaminhamentos variam de acordo com os casos. É importante observar também que, a compreensão sobre a importância de um trabalho multidisciplinar está sendo ampliada. Se antes, os médicos e psicólogos eram contrários aos tratamentos feitos em conjunto, nos dias atuais, o trabalho destes profissionais vem sendo requisitado, reciprocamente (KIMURA, 2005).

Apesar das disciplinas apresentarem olhares diferentes sobre o paciente, elas se completam. Desta forma, este, não pode ser visto apenas através dos ângulos biologistas ou psicologistas, mas em um contexto biopsicossocial. Portanto, o ideal é que seja feito um trabalho em conjunto (OCCHINI; TEIXEIRA, 2006).

Quando o encaminhamento é necessário, independente da fase da psicoterapia em que se perceba essa importância, é preciso que o terapeuta explique para o seu paciente o motivo desse encaminhamento para que este tenha tempo de considerar essa questão e de dar as suas repostas referentes a ela (SAFFER, 2007).

No grupo CAPS, dois "Sempre" encaminham e sete encaminham "Às vezes". Nenhum encaminha "Raramente" ou "Nunca". Já no Grupo Três, quatro encaminham "Às vezes" e um "Sempre" encaminha os seus pacientes aos psiquiatras. Nenhum encaminha "Sempre", "Raramente" ou "Nunca". Portanto, os grupos demonstraram não ter uma diferença considerável neste quesito, sendo que, os três grupos demonstraram mais que encaminham, “Às vezes". Contudo, o Grupo Centros de Saúde, foi o único a apresentar a resposta "Raramente". Mostrando assim, uma pequena resistência. Essa dificuldade, mesmo que pequena, dos psicólogos em encaminhar seus pacientes aos psiquiatras pode ser explicada pelo fato dessas profissões serem vistas tradicionalmente como competitivas ao invés de colaboradoras (GABBARD, 1994).

Fractal, Rev. Psicol., v. 30 - n. 2, p. 281-290, 2018
Figura 7 - Como você percebe a relação entre psicólogos e psiquiatras, no âmbito da saúde mental?

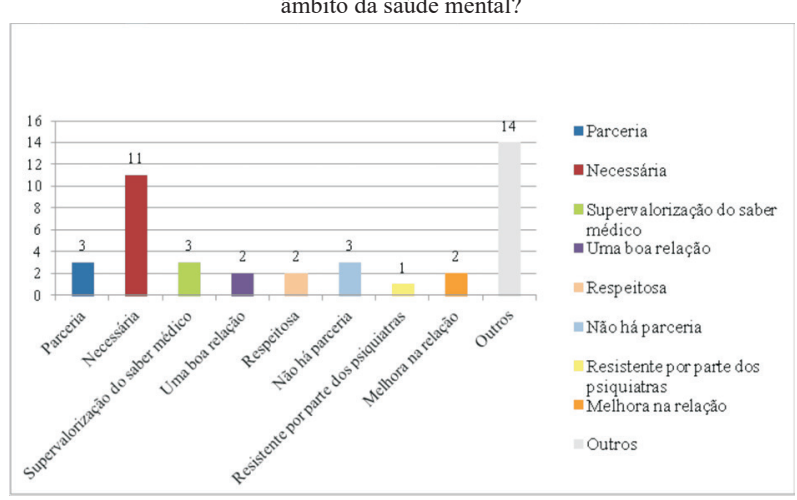

Fonte: Elaborado pelas autoras com dados de 2015, coletados através de questionários aplicados em psicólogos da Secretária Municipal de Saúde de Montes Claros - MG.

A figura 7 representa a questão seis do questionário desta pesquisa, sendo esta, uma questão aberta. Sendo assim, os psicólogos citaram quatorze percepções dessa relação, como: "Conflitante"; "Com pouca Interação"; "Difícil, mas com tendência a mudanças"; com "Pouca Abertura", com "Boa Compreensão mútua entre papéis"; com "Submissão dos psicólogos"; "Interdisciplinar"; de "Interação"; entre outras. Por se tratar de uma questão aberta, alguns psicólogos citaram mais de uma percepção sobre a relação entre psicólogos e psiquiatras.

Percebe-se por meio deste gráfico que, as respostas que os psicólogos mais citaram referente à compreensão da relação com os psiquiatras, foram que esta relação é "Necessária" e de "Parceria". Essa compreensão é importante, pois a participação e o envolvimento de todos os profissionais na assistência à saúde favorece melhor disponibilidade destes para com os seus pacientes. Além disso, o atendimento à saúde necessita de uma resolutividade, uma vez que, é essencial uma solução dos problemas de saúde para a humanização da assistência (HOGA, 2004).

Houve também, alguns psicólogos que colocaram que existem dificuldades na relação com os psiquiatras, alegaram que esta se trata de uma relação "Conflituosa", que "Não há Parceria", "Com pouca Interação" e que, nessa relação "há uma Supervalorização do saber médico". Contudo, eles citam também que existe uma Submissão do psicólogo nessa relação com o psiquiatra. Essas questões surgem então, com uma competição entre estes profissionais ao consideraram que os seus saberes são superiores aos demais, caracterizando assim, uma resistência ao progresso terapêutico (SAFFER, 2007).

Um dos principais fatores que dificultam também a prática da interdisciplinaridade é a preferência, das equipes de profissionais, pelo trabalho individual em relação ao coletivo (NECKEL, 2009). É necessária que a prática entre psiquiatra e psicólogo seja estrutural e que permita uma reciprocidade, um enriquecimento mútuo e uma relação horizontal, sem hierarquias de poderes, entre essas duas profissões (VASCONCELOS, 2002).

Para que não exista uma relação competitiva de saberes ou uma submissão por parte dos psicólogos, é importante que os psicólogos demonstrem o seu conhecimento e que possuem um conhecimento básico sobre psicofar- 
macologia e sobre a psicopatologia; Para os psiquiatras, é importante que compreendam sobre o processo psicodinâmico (SAFFER, 2007).

No Grupo Centros de Saúde, os psicólogos disseram que compreendem a relação entre psicólogos e psiquiatras como uma relação "Necessária", "Boa", e de "Compreensão Mútua dos papéis”. Contudo, eles citaram muitas Dificuldades nessa relação, colocando que, se trata de uma relação "Complicada", "Com pouca abertura", "Conflitante", "Difícil” (mas que tende a mudanças) e que existem também: uma "resistência por parte dos psiquiatras", uma "necessidade de interação" e uma "supervalorização do saber médico".

Os psicólogos do Grupo CAPS, citaram também algumas dificuldades nessa relação com os psiquiatras. Citaram assim, que esta relação "possui falhas na rede"; que "precisa de parceria"; e que uma "relação desigual", que existe uma "supervalorização do saber médico"; e que essa relação é "às vezes de parceria" e "às vezes conflituosa". No entanto, esse grupo citou mais aspectos positivos do que negativos nessa relação, sendo esta, "Tranquila", "Respeitosa", de "Parceria", "Necessária", de "Interação" e que é uma relação que vem "Melhorando devido à importância do psicólogo no tratamento do paciente".

Já no grupo Três, os psicólogos colocaram que percebem que existe uma "Boa relação", que está "Melhorando"; que é uma relação "Necessária", principalmente quando há respeito do saber do outro; de "Parceria"; "Complementar"; e "Interdisciplinar". Sobre as dificuldades percebidas por estes psicólogos, foram citadas que é uma relação de "Submissão dos psicólogos à prática médica" e que há uma "Supervalorização do saber médico".

Grande parte da dificuldade enfrentada pelos psicólogos na relação com os psiquiatras deve-se a questão de que nem todos os Serviços de Saúde possuem uma equipe integrada, ficando estas à mercê do olhar do gestor local. Portanto, esta ausência do psiquiatra acaba atrapalhando, a relação e a comunicação entre os psicólogos e psiquiatras, tornando-a dispendiosa e difícil, visto que, ainda que, o psicólogo perceba a necessidade de comunicação com o psiquiatra, é ele quem deve encontrar uma forma de ir até ele.

De acordo com as respostas dos psicólogos, a dificuldade nessa relação com os psiquiatras é percebida por eles, como um distanciamento e uma supervalorização do saber médico, ou seja, os psicólogos percebem que, em grande parte, a responsabilidade desse distanciamento é dos psiquiatras. Contudo, surge um questionamento de que, se essa aproximação deve ser feita apenas pelo psiquiatra ou por ambos os profissionais. Além disso, para que o psicólogo seja reconhecido nessa relação profissional, é necessário que este, faça reconhecer o seu saber, demonstrando sua importância no tratamento psicoterápico. Esta questão é explicada pelo fato de que, a primeira condição para um trabalho disciplinar do psicólogo, é a clareza quanto as suas atribuições e quanto às expectativas da sua especificidade (ROMANO, 1999).

\section{Questão 7}

A análise abaixo diz respeito à questão 7 , nela os psicólogos pesquisados poderiam colocar algo a mais a respeito do tema e/ou da pesquisa, ou seja, o que gostariam de acrescentar. Tratou-se neste caso, de uma questão aberta.

\section{Grupo Centro de Saúde}

Neste grupo, um psicólogo colocou que é necessário que seja implantado o Núcleo de Apoio a Saúde da Família - NASF e que haja disposição dos psicólogos atuantes em seguir as diretrizes do programa e, um psicólogo pesquisado colocou que é necessário que haja interlocução de profissionais na Rede de Atenção Psicossocial - RAPS.

\section{Grupo CAPS}

No Grupo CAPS, em relação à questão dois do questionário, um psicólogo justificou dizendo que respondeu "Raramente" porque o psicofármaco pode significar um empecilho no tratamento psicológico. Outro psicólogo citou também que, há uma deficiência significativa dos psicólogos a respeito do conhecimento da psicofarmacologia e psicopatologia. Portanto, é necessária maior atenção das Instituições de Ensino e dos Serviços Públicos a este respeito.

\section{Grupo Três}

Do grupo Três, dois psicólogos se manifestaram. Um salientou que, os psicólogos de Rua possuem uma escuta diferenciada por atender nas ruas. Que é necessário assim, dispor de todo e qualquer preconceito. Outro citou a importância da pesquisa devido ao aumento dos diagnósticos psicológicos, pois, há necessidade de cautela no que se diz respeito aos psicofármacos, visto que, o sujeito está além dos sintomas.

Foi percebido, através das respostas dos psicólogos através dos questionários que, eles dizem de uma necessidade de reciclagem (treinamento e capacitação), e que, para eles, esta deve ser oferecida pelos Serviços da secretaria Municipal de Saúde, com estudos sobre a psicopatologia, psicofarmacologia e sobre o trabalho multidisciplinar, justificando assim, existir uma carência desses saberes por parte dos psicólogos. Essa necessidade é explicada pelo fato de que a formação dos psicólogos ainda possui uma proposta tradicional, com uma formação clássica, que os deixa assim, sem ferramentas teóricas para o trabalho nos Serviço do Sistema Único de Saúde -SUS (PAULIN; LUZIO, 2009). Sendo assim, é importante ressaltar que, de acordo com o parágrafo vinte e sete da lei 8.080 de 1990, estes servidores possuem o direito a formação em todos os níveis de ensino, inclusive de pós-graduação, além da elaboração de programas de permanente aperfeiçoamento de pessoal.

Diante da percepção dos psicólogos pesquisados sobre o distanciamento dos psiquiatras, nota-se uma necessidade de se pesquisar também sobre a percepção dos psiquiatras acerca da relação destes com os psicólogos e sobre os impasses que atrapalham essa relação. 
Percebe-se então que, a maioria dos psicólogos pesquisados encaminha seus pacientes aos psiquiatras, bem como, acreditam na necessidade da utilização dos psicofármacos, mesmo que "Às vezes", ou seja, quando necessário, podendo demonstrar assim, uma forma de atuação ética e profissional, da parte destes psicólogos, visto que compreendem a importância dos psicofármacos.

Através desta pesquisa, foi percebida uma necessidade do Conselho Regional de Psicologia em conhecer o trabalho desenvolvido por estes profissionais psicólogos na cidade de Montes Claros - MG, visto que, foi notada a existência de alguns Psicólogos que atuam de forma contrária às normas do Código de ética do psicólogo, utilizam inclusive, de Teorias não reconhecidas pela Ciência Psicológica, no atendimento de seus pacientes.

\section{Conclusão}

Através dos dados e da articulação teórica, foi possível compreender que a maioria dos psicólogos percebem os psicofármacos como auxiliadores no processo psicoterápico e que concordam que alguns pacientes necessitam utilizar os psicofármacos durante este processo. Contudo, foi observado que muitos dos psicólogos pesquisados, ainda possuem dificuldades quanto à relação com os psiquiatras, havendo assim, certo distanciamento entre eles.

Por fim, acredita-se que este trabalho alcançou seu objetivo, visto que, possibilitou compreender como se encontra, atualmente, o cenário do atendimento psicológico na rede da Secretaria Municipal de Saúde de Montes Claros - MG. Tornou possível também uma reflexão a respeito do tema, pois, ao conhecer a percepção dos psicólogos sobre os psicofármacos aliados à psicoterapia e sobre a relação psicólogo/psiquiatra, novas formas de pensar e agir do psicólogo, em seu contexto de trabalho, foram possibilitadas. Além disso, foram percebidas pelas pesquisadoras, ao longo da confecção deste trabalho, dificuldades em encontrar estudos científicos sobre o tema. Desta forma, esta pesquisa contribui à ciência psicológica e ao trabalho do psicólogo.

\section{Referências}

AROUCA, S. Reforma sanitária. Rio de Janeiro, 1998. Disponível em: http://bvsarouca.icict.fiocruz.br/sanitarista05. html. Acesso em: 30 out. 2014.

BARREIROS, J. A. B. A. Explicitação dos processos de mudança em psicoterapia de orientação psicodinâmica em pacientes com dor crônica. 2012. Dissertação (Mestrado em Psicologia Clínica), Instituto Universitário, Lisboa, Portugal, 2012. Disponível em: http://hdl.handle.net/10400.12/2566. Acesso em: 27 jun. 2016.

BENIA, L. R. Desemprego: luto ou melancolia. 2000. $110 \mathrm{f}$. Dissertação (Mestrado em Psicologia Social e Institucional) Universidade Federal do Rio Grande do Sul, Rio Grande do Sul, 2000.

BEZERRA, M. L. M. Psicofarmacologia e psicoterapia: mitos, benefícios e interferências. In: ENCONTRO PARANAENSE, CONGRESSO BRASILEIRO, CONVENÇ̃̃O BRASIL/ LATINO-AMÉRICA, 13., 8., 2., 2008. Anais... Curitiba: Centro Reichiano, 2008. CD-ROM.
BIRMAN, J. Mal-estar na atualidade: a psicanálise e as novas formas de subjetivação. 3. ed. Rio de Janeiro: Civilização Brasileira, 2000.

BOTEGA, N. J. Prática psiquiátrica no hospital geral. Porto Alegre: Artmed, 2001.

BRASIL. Ministério da Saúde. Conselho Nacional de Saúde. Resolução 196/96 de 14 de janeiro de 1987. Diretrizes e normas regulamentadoras de pesquisas envolvendo seres humanos. Disponível em: http://www.ufrgs.br/bioetica/res19696.htm. Acesso em: 15 ago. 2014.

CABRAL, A. C. C.; FABRI, R. F. Conhecimento sobre a doença e expectativas do tratamento em familiares de pacientes no primeiro episódio psicótico: um estudo transversal. Revista de Psiquiatria do Rio Grande do Sul, Rio Grande do Sul, v. 27, n. 1, p. 32-38, jan./abr. 2005. Cross ${ }^{\text {Ref. }}$

CANGUILlHeM, G. O Normal e o patológico. Tradução de Maria Tereza Redig de Carvalho Barrocas. 6. ed. Rio de Janeiro: Forense Universitária, 2006.

CARDOSO, L; GALERA, S. A. F. Doentes mentais e o seu perfil de adesão ao tratamento psicofarmacológico. Revista da Escola de Enfermagem da USP, São Paulo, v. 43, n. 1, p. 161167, mar. 2009. Cross ${ }^{\text {Ref. }}$

CARVALHO, S. R. et al. Medicalização: uma crítica (im) pertinente? Physis, Revista de Saúde Coletiva, Rio de Janeiro, v. 25 , n. 4, p. 1251-1269, out./dez. 2015. Cross ${ }^{\text {Ref. }}$

CONSELHO FEDERAL DE PSICOLOGIA. Resolução n. 010/05, de 12 de maio de 2005. Código de Ética Profissional do Psicólogo. 2005. Disponível em: https://site.cfp.org.br/ wp-content/uploads/2012/07/codigo-de-etica-psicologia.pdf. Acesso em: 20 abr. 2016.

CORDEIRO, H. O Instituto de Medicina Social e a Luta pela Reforma Sanitária: Contribuição à História do SUS. Physis: Revista de Saúde Coletiva, Rio de Janeiro, v. 14, n. 2, p. 343362, jul. 2004. Cross ${ }^{\text {Ref. }}$

CURY, J. A. Inteligência multifocal: análise da construção dos pensamentos e da formação dos pensadores. São Paulo: Pensamento/Cutrix, 1998.

EELLS, T. D. Psychotherapy versus medication for unipolar depression. Journal of Psychotherapy Practice and Research, v. 8, n. 2, p. 170-173, 1999.

FRANCO, L. T. A impressão de psicoterapeutas em treinamento sobre a importância de psicotrópicos para o tratamento de sofrimentos psíquicos. 2012. Trabalho de Conclusão de Curso (Graduação em Psicologia)-Universalidade Católica de Brasília, Brasília, 2012. Disponível em: https://repositorio. ucb.br/jspui/bitstream/10869/5681/5/La\%C3\%ADs\%20 Tartuce\%20Franco.pdf. Acesso em: 18 out. 2015.

FREY, B. N.; MABILDE, L. C.; EIZIRIK, C. L. A integração da psicofarmacoterapia e psicoterapia de orientação analítica: uma revisão crítica. Revista Brasileira de Psiquiatria, São Paulo, v. 26, n. 2, p. 118-123, 2004. Cross ${ }^{\text {Ref }}$

GABBARD, G. O. Psiquiatria psicodinâmica: baseado no DSM-IV. 2. ed. São Paulo: Artes Médicas Sul, 1994.

GENTIL, V. et al. Clomipramine-induced mood and perceived performance changes in selected healthy individuals. Journal of Clinical Psychopharmacology, v. 27, n. 3, p. 314-315, jun. 2007. Cross ${ }^{\text {Ref }}$ 
HOGA, L. A. K. A dimensão subjetiva do profissional na humanização da assistência à saúde: uma reflexão. Revista da Escola de Enfermagem da USP, São Paulo, v. 38, n. 1, p. 13-20, mar. 2004. Cross ${ }^{\mathrm{Ref}}$

KIMURA, A. M. Psicofármacos e psicoterapia: a visão de psicólogos sobre medicação no tratamento. 2005. Trabalho de Conclusão de Curso (Graduação em Psicologia)-Faculdade de Ciências Humanas e Sociais da Universidade São Judas Tadeu, São Paulo, 2005. Disponível em: http://newpsi.bvs-psi.org.br/ tcc/220.pdf. Acesso em: 22 out. 2015.

MACHADO, J. S. A. Gênero sem razão: mulheres e loucura no sertão norte mineiro. 2009. Dissertação (Mestrado) Universidade Estadual de Montes Claros, Montes Claros, 2009. Disponível em: http://livros01.livrosgratis.com.br/cp115728. pdf. Acesso em: 12 jan. 2015.

MENDONÇA, A. M. G. Reforma psiquiátrica em Montes Claros: Perspectiva Histórica. 2009. Dissertação (Mestrado em Desenvolvimento Social)-Universidade Estadual de Montes Claros, Montes Claros, 2009. Disponível em: http://ivros01. livrosgratis.com.br/cp115727.pdf. Acesso em: 20 dez. 2017.

NECKEL, G. L. et al. Desafios para a ação interdisciplinar na atenção básica: implicações relativas à composição das equipes de saúde da família. Ciência e Saúde Coletiva, Rio de Janeiro, v. 14 (supl 1), p. 1463-1472, set./out. 2009. Cross ${ }^{\text {Ref }}$

OCCHINI, M.; TEIXEIRA, M. Atendimento a pacientes dependentes de drogas: atuação conjunta do psicólogo e do psiquiatra. Estudos de Psicologia, Natal, v. 11, n. 2, p. 229-236, maio/ago. 2006. Cross ${ }^{\text {Ref }}$

PAULIN, T.; LUZIO, C. A. A Psicologia na Saúde Pública: desafios para a atuação e formação profissional. Revista de Psicologia da UNESP, Assis, v. 8, n. 2, p. 98-109, 2009. Disponível em: http://observatoriodasauderj.com.br/wpcontent/uploads/2017/05/A_Psicologia_na_Saude_Publica_ desafios_p.pdf. Acesso em: 23 jun. 2015.

POWELL, A. D. The medication life. The Journal of Psychotherapy Practice and Research, v. 10, n. 4, p. 217-222, 2001. Disponível em: https://www.ncbi.nlm.nih.gov/pmc/ articles/PMC3330671/. Acesso em: 15 mar. 2016.

RIBEIRO, J. P. Processo de mudanças em psicoterapia: reflexões sobre uma teoria da psicoterapia. Arquivo Brasileiro de Psicologia, Rio de Janeiro, v. 36, n. 2, p. 99-107, abr.jun. 1984. Disponível em: http://bibliotecadigital.fgv.br/ojs/index. php/abp/article/viewFile/18987/17727. Acesso em: 15 mar. 2016.

ROMANO, B. W. Principios para a prática da psicologia clínica em hospitais. São Paulo: Casa do Psicólogo, 1999. SAFFER, P. L. O desafio da integração psicoterapiapsicofarmacoterapia: aspectos psicodinâmicos. Revista de Psiquiatria do Rio Grande do Sul, Porto Alegre, v. 29, n. 2, p. 223-232, ago. 2007. Cross ${ }^{\mathrm{Ref}}$

SADOCK, B. J. Signs and Symptoms in Psychiatry. In: SADOCK, B. J.; SADOCK V. A. (Ed). Comprehensive textbook of psychiatry. 7th ed. Baltimore: Lippincott Williams \& Wilkins, 2000. p. 677-89.

TELES, M. L. S. O que é Psicologia? São Paulo, 2003.

TENGAN, S. K.; MAIA, A. K. Psicoses funcionais na infância e adolescência. Jornal de Pediatria, Rio de Janeiro, v. 80, n. 2, supl. p. 3-10, abr. 2004. Cross ${ }^{\text {Ref. }}$
VASCONCELOS, E. M. (Org.). Saúde mental e serviço social: o desafio da subjetividade e da interdisciplinaridade. São Paulo: Cortez, 2002.

Recebido em: 12 de novembro de 2015 Aceito em: 16 de janeiro de 2018 